\title{
PLIOCENE DEPOSITS ON THE SOUTH DOWNS.
}

SIR,-May I call attention to the discovery by Mr. W. J. Lewis Abbott some years ago of Pliocene deposits on the South Downs? His paper "On the Pliocene Deposits of the South-East of England", Proc. of the Prehistoric Soc. of East Anglia, vol. ii, 1915-16, part ii (reference to the South Downs on pp. 182 and 186) appears to have been overlooked.

I have been in communication with Mr. Abbott on this subject, and find that he has made a collection of specimens of fossiliferous ferruginous sandstone from the top of the Downs near Beachy Head and Willingdon, in which Mr. C. P. Chatwin recognizes the fauna of the Lenham Beds. These specimens are now in the Museum of Practical Geology.

Recently, in company with Mr. S. W. Hester, I have had the opportunity of examining ferruginous sandstone in the field in the Beachy Head district. This sandstone is present in some quantity and, while largely unfossiliferous, some blocks found yielded marine fossils of Pliocene age.

This subject is under further consideration.

F. H. Edmunds.

\section{HEAVY MINERAL FREQUENCIES.}

Sir,-May I be permitted a few observations in reply to Mr. Stuart's letter of your March issue ? Regarding Mr. Stuart's first point I would state that the Old Red Sandstone residues were mounted in their entirety, and therefore the actual heavy-mineral composition is accurately represented by the percentage-figures. It is understood, of course, that a sufficient number of representative samples must be examined and one of the chief aims of my communication was to show the remarkable general uniformity of results obtained at different horizons in the Old Red Sandstone of the West Midlands.

Referring to the connexion between variation in mineralcomposition and distance from supply-source, this is well and concisely stated by Mr. S. W. Wooldridge in his letter in the February issue of this Magazine (p. 95). Mr. Wooldridge, speaking of the Diestian deposits, says: "Over a wider area a significant regional gradation of the percentages can be detected-a regular increase in the percentage of stable species in the direction of transit of the material pointing to progressive elimination of the less resistant mineral-types." The weight of heavy mineral residue per unit weight of sediment would diminish as a result of attrition with increasing distance from supply-source, but in practice the adoption of Mr. Stuart's plan of weighing the a mounts of residue, though perhaps desirable as providing additional data, is not likely to be easy, chiefly 
because, in many sands, the weight of heavy residues is extremely small.

The main objection to Mr. Stuart's third suggestion as to the desirability of including grain-size in the percentage frequency tables would seem to be practical difficulty when dealing with large numbers of grains, say 1,000 or 1,500, in a residue. Making due allowance for Mr. Stuart's useful criticism and suggestions one must beware of over-elaboration if the general worker in geology is not to be unduly deterred by the specialist's refinements. It is certain that the latter, combined with due caution in interpreting results, will lead to interesting conclusions regarding the deposition of sediments, but the main purpose of the original communication was to show that the accurate counting and simple percentage representation of heavy minerals in sedimentary rocks, with due regard to variation in habit, size, etc., are operations easily carried out with results that are readily comparable with those obtained by others.

W. F. Fleet. 